\title{
Primary anorexia nervosa (weight phobia) in males
}

\author{
M. K. HASAN* \\ M.R.C.Psych., D.P.M.
}

\author{
R. W. TibBetts $\dagger$ \\ F.R.C.Psych., D.P.M.
}

Birmingham Area Health Authority (Teaching)

\section{Summary}

Ten cases of primary anorexia nervosa (weight phobia) in males (as against 196 females) have been treated in the United Birmingham Hospitals over 19 years.

A discrete syndrome appears to exist with much to support the view that it is the counterpart of primary anorexia nervosa in the female. Six illustrative case histories are described briefly. The heavy loading with consistent abnormalities of psychiatric interest makes it very probable that weight phobia is primarily a psychiatric disorder.

\section{Introduction}

Primary anorexia nervosa is receiving special emphasis at the present time, and there is a general impression that the incidence has increased in the last decade (Bliss and Branch, 1960; Theander, 1970; Kendell et al., 1973; Crisp, Palmer and Kalucy, 1976). It is difficult to be sure to what extent the increase is real and to what extent it reflects fashion and cultural influences, the epidemiological potential of the media (especially television) or a greater awareness of the condition amongst doctors.

Whereas patients whose anorexia is secondary to depression or some other disorder are not slow to seek help, it is in the very nature of primary anorexia nervosa to avoid such help, so that the condition in its less severe form is probably commoner than is at first apparent.

Until recent years it was widely held that anorexia nervosa was by definition a disorder of women. This non-recognition meant that a condition, admittedly very rare in males, appeared even rarer. In general, a 'chubby' boy will be under less social and domestic pressure than his sister in a similar condition. In the female, puberty declares itself in more concrete form or earlier than in the male. Crisp (1970) suggested that homosexual conflict in the male may play a comparable role to that of the heterosexual threat in the female.

The rarity of primary anorexia nervosa in the male sex is not in question but it is equally certain that a

\footnotetext{
* Present address: Department of Psychiatry, Appalachian Regional Hospital, Beckley, West Virginia 25801, U.S.A.

$\dagger$ Present address: The Midland Nerve Hospital, Elvetham Road, Birmingham B15 2NJ.
}

condition exists in males which coincides closely with the female equivalent. Bruch (1973) has described ten cases but four of these were depresset and probably secondary.

Crisp and Toms (1972), in a report on thirteen male patients with anorexia nervosa, concluded that. the disorder has the same characteristics as the fes male version and includes active avoidance os normal weight, elective carbohydrate starvation and emaciation.

\section{Case reports and methods}

Because of the limited number of cases of malo anorexia on record, it was felt that an account of another ten cases would be worthwhile. The present. findings are reported under the headings similatot\& those employed by Crisp and Toms (1972) and are gratified by the degree of concordance that emergig

The study necessarily involves some of those short comings inherent in retrospection, but it is nō thought that this has proved misleading to a signiö ficant degree, since the hospital records are gratifyingly complete.

No patient came on his own initiative to seek psychiatric help, and most consulted a doctor only under considerable family pressure. The generạ. practitioner usually referred the patient to a physie cian in the first place, and the initial screening was ap. advantage where it was not protracted in such a way as to prejudice the psychiatric approach to the pro 0 . blem. The immediate referral was from a physicia in eight cases and a general practitioner in two.

Notes were obtained through computer record? and a large number of case notes were scrutinized and only those with the following criteria were. accepted.

(1) Avoidance of food, and especially carbohydrates, with evidence of deliberate deceit aboup food intake or weight.

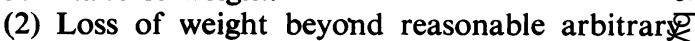
limits.

(3) Absence of an adequate explanation for th weight loss, either from organic disease or primary ${ }^{+}$ psychiatric disorder, especially depression.

A few short case histories now follow to illustrate्ष the types of problem which were encountered. 
Case 1 (age 21 years)

A single man had an i.q. of 130 but his emotional problems had prevented his putting his potential to good use. When he was 17 years old his father died from carcinoma of the stomach. He had been rather a remote man and the patient felt guilty that the bereavement did not make a greater impression on him. His mother was the dominant partner and the relationship a close one.

A combination of events occurred, including his father's death, the prospect of A levels, intense awareness of his adolescent status and concern over his excess weight. He was seen by a colleague, who found him to te notably depressed and who prescribed ECT but without relief of symptoms. His weight had fallen from $67 \cdot 1$ to $44 \cdot 5 \mathrm{~kg}$.

Sexually, there were heterosexual phantasies at first and there was from the age of 16 a relationship protracted for 2 years with a girl who played the dominant role; the sexual implications were minimal. Later his homosexual conflicts declared themselves as a focal point and he proved a good subject for treatment by systematic psychotherapy. In hospital, the familiar features were prominent, with mounting evidence of tension, deceit concerning intake, surreptitious superflous exercise (press-ups throughout the day), unremitting preoccupation with weight and resentment and depression if forced to eat-an unequivocal case of anorexia nervosa and weight phobia. Following discharge he held various jobs, including an unrewarding escape to the Marines.

\section{Case 2 (age 15 years)}

Seen by a child psychiatrist at the age of 11 with prodromal symptoms of anorexia which, however, declared itself more floridly at the age of 14 . He was self-conscious about being called 'podgy' and lost $12.7 \mathrm{~kg}$. He was very active until his physical state made him abnormally tired. The home background was happy enough. His mother was nervous and took chlordiazepoxide; his attitude to her was ambivalent. The parents were in the catering trade. He himself was faced with A levels for which he had sufficient potential. He became deeply depressed and, in all, made three suicidal gestures, mostly when he felt guilty because of eating. He had an intense fear of masculinity and sexuality and at one point this was so pronounced that a diagnosis of schizophrenia was considered but nothing emerged to substantiate this. In hospital this very thin young man showed hepatomegaly and hypotension. His general appearance was effeminate and there was absence of secondary sexual characteristics. On this account, chromosome studies were performed but proved normal. A low plasma testosterone figure was reported $(20 \mathrm{ng} / 100 \mathrm{ml})$ and this was considered to be within a low prepubertal range. In hospital he showed strong obsessional features, particularly after seeing television programmes about sexuality and violence. He made good progress but was readmitted after 5 months because of a reassertion of symptoms.

\section{Case 3 (age 7 years)}

Encopresis for 3 years; enuresis of longer duration; anorexia for 3 months. Weight $20 \mathrm{~kg}$.

A provocative home situation with bad housing conditions. His parents were very inconsistent in their management and this was particularly true of his father. He lost his symptoms when he went to stay with an aunt.

In hospital, hypotension was found but no other abnormality.

Although before admission he seemed to show a genuine and powerful avoidance of food, this disappeared almost immediately after admission. Circumstances dictated that he be treated in a ward mainly with adults and since at his best he was an engaging child he became the focus of attention and gloried in it. Alimentary problems with output or input ceased and he was discharged a happy boy to an open air school.

Originally he was categorized as a case of anorexia nervosa and in a sense this was justified since anorexia was the symptom he paraded. There was, however, no evidence of weight phobia and the final appraisal was that of a disturbed child reacting to an unhappy situation.

The case is described to illustrate an example of a problem finally rejected for the purpose of this series.

\section{Case 4 (age 29 years)}

A married man; i.q. about 80. An immature personality with a poor work record. Onset age 27 with aversion to food but more particularly bulimia and very frequent induced vomiting. He was withdrawn, mildly paranoid and with offensive habits. A provisional diagnosis of schizophrenia in a dullard was made but not substantiated. His weight fell from $72 \cdot 2$ to $45 \cdot 4 \mathrm{~kg}$. His father's death from carcinoma of the stomach preceded the onset of the patient's illness and he had a very bad relationship with an affectionless and neurotic mother. He married a woman more attractive and competent than himself. The courtship was characterized by threats of suicide, a gesture of burning his hand and other attention-seeking behaviour. As the illness proceeded, normal libido declined completely. Finally his wife, not without conflict and constructive effort, left him.

On admission, serum electrolytes were very disturbed and there was a raised serum urea. He was very fully investigated by a physician who regarded 
the vomiting as hysterical. In hospital he concealed his vomit in all kinds of containers.

Shortly after discharge he relapsed and his behaviour became depraved and confused, no doubt in association with serious metabolic disturbance. $\mathrm{He}$ was re-admitted to the General Hospital, Birmingham, where he soon died.

Some might maintain that the psychopathic colouring, with various hysterical manifestations and the personality disorder, demanded a diagnosis of secondary rather than primary anorexia nervosa. Nevertheless, the picture of bulimia with deliberate vomiting was the dominant theme; true weight phobia was evident and the basic preoccupation. The authors feel justified in including this case in the series.

\section{Case 5 (age 27 years)}

A university graduate; married with a child aged 2 years. Admitted with sudden weakness of the legs under the care of a physician in July 1970. Carcinomatous neuropathy was considered but investigations were reassuring and he was later referred as a case of anorexia nervosa. This man was $1.9 \mathrm{~m}$ tall, and started to lose weight originally during his wife's pregnancy, a fact which may well have significance, and not only because she was unable to supervise him as closely as usual. He lost $19.1 \mathrm{~kg}$ in the last 5 months before admission, at which time he was very emaciated. It was his practice to get up at 5.0 a.m. and to take a great deal of exercise. A marriage hitherto happy enough became otherwise, and his wife made a token separation. Libido declined entirely and there was suicidal contemplation. The previous background was one of a very close relationship with a mother who died of leukaemia, and conflict over the resentment which he felt towards a very successful father who died 2 years before the patient's admission. Following this he strove to succeed in business in which he was making, as it were, an effort to appease his father, and no doubt his very obsessional personality was the outcome of that relationship.

At home he took great pleasure in cooking for his wife and gave himself exactly half portions, carefully measured, which, however, by deceitful means he failed to swallow.

Investigations revealed hepatomegaly and there was evidence of liver damage and normocytic anaemia. The most striking feature, however, was marked steatorrhoea and it was on this account that advice was sought of a consultant gastroenterologist. A barium meal showed some abnormalities but a jejunal biopsy was normal. The consultant felt at this stage that the likelihood was that of primary organic disease but when the abnormal physical findings were reversed as he gained weight this opinion was revised with general agreement to
diagnosis of anorexia nervosa.

In this case there are some atypical features ande also interesting reversible organic findings. After close study, however, no reason was found to $?$ exclude him from the series.

Case 6 (age 21 years)

A single man; an only child, of above average $\mathbb{E}_{0}$ intelligence. Referred by a physician after initiaw clinical screening. Onset 3 years previously with loss of weight from 73 to $41.3 \mathrm{~kg}$ with tiredness? and weakness on exertion for 8 months. His plump $\vec{\omega}$ ness was brought home forcibly to him, when he wase 17 years old, when three girls in succession calle $\bar{B}$ him 'fatty'. Reasonable dieting took on irrationa $\mathrm{B}$. and compulsive qualities, especially where carbo $\mathrm{j}$ hydrates were concerned. He took excessive exercise running upstairs twelve times a day and doing fre $\vec{v}$ quent press-ups. When he was $50.8 \mathrm{~kg}$ he completed a charity walk of 21 miles without taking any foodo He discussed food a great deal and enjoyed cookings for others. He had considered this as a career. There was no heterosexual or homosexual activity.

In hospital he behaved with characteristic evasive ness but one unusual event occurred: he was put on chlorpromazine $100 \mathrm{mg} /$ day and developed an acôtt dystonic reaction with caused him the greatest

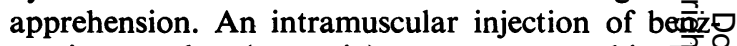
tropine mesylate (cogentin) soon overcame this. The dose of chlorpromazine was reduced and procy릉 clidine hydrochloride (kemadrin) $5 \mathrm{mg}$ t.d.s. was prescribed. Soon he relapsed into a toxic confusiona $\$$ state with paranoid features and visual hallucina tion. All the evidence pointed to this being due tôे procyclidine.

He was indulged in his impression that this was calculated part of the treatment; this ancillar form of operant conditioning proved a turning poin $\underline{\underline{B}}$. for the good in his outlook and co-operation.

\section{Discussion}

The authors were fortunate in being able to obtai from the Statistical Department the incidence o $\Phi$ anorexia nervosa in the United Birmingham Hospitals from 1956 to 1975, and after scrutiny of the notes. and elimination of unconvincing cases of primary anorexia nervosa the figures are as shown in Table ị This confirms the overall increase of cases of females anorexia nervosa in recent years, for some reasof with a peak in 1973. Over the years in question there has been no increase in the out-patient load or bed availability such as might explain the figure artefactually.

The female to male ratio $(196: 10)$ is in keeping with other reports. Crisp and Toms (1972) speak of the reported range as varying from $10: 1$ to $20: \mathbb{R}$ 
TABLE 1. Incidence

\begin{tabular}{lcr}
\hline & Male & Female \\
\hline 1975 (Jan/June) & 1 & 9 \\
1974 & 2 & 20 \\
1973 & 1 & 40 \\
1972 & 1 & 13 \\
1971 & 2 & 17 \\
1970 & & 18 \\
1969 & & 22 \\
1968 & & 14 \\
1967 & & 11 \\
1966 & 1 & 7 \\
1965 & 1 & 6 \\
1964 & & 8 \\
1963 & 1 & 11 \\
1956 & 10 & 196 \\
Total & & \\
\hline
\end{tabular}

\section{Clinical data}

Table 2 compares the present findings with those of Crisp and Toms (1972) for certain factors and there is considerable concordance. Birth weight and duration of breast feeding were not recorded in sufficient detail to justify inclusion.

In general the mother appeared to play the dominant role and also to be the more approachable parent from the patient's point of view. In three cases there was frank over-dependence on the mother. The fathers were the ones to get most upset about the patients' eating habits and perhaps tolerate such behaviour more easily in children of the opposite sex. The family history of psychiatric illness followed the same type of distribution as that described by Crisp and Toms (1972), that is to say it was moderately prominent but not invariable.

There were no instances of drug dependence unless one includes in this category three men who deliberately smoked to great excess to contain their appetites. One patient developed secondary dependence on alcohol. No patient displayed any evidence of clinical epilepsy and unlike Crisp and Toms (1972) this is something we have never met in female anorexics in spite of the large numbers. An interest in providing food for others is common, and no less than three of the young men spontaneously expressed a wish to become chefs or to take up catering as a career. Restlessness and over-activity were noted beyond normal expectation and affective disturbance was common. This included anxiety, irritability, tension and agitation, as well as frank depression. This appeared as a rule to be secondary to frustration at a stage in their illness when weakness and tiredness were restricting their activities, or as a reaction to guilt when medical treatment or natural inclination induced them to take food which they wished to avoid. Three patients presented in a way that caused speculation as to a psychotic process but in no case was the evidence for this convincing in the longer term. Suicidal ideas were expressed in three cases but not in a manner to cause serious concern, with the exception of case 4 whose death secondary to prolonged vomiting could in a sense be regarded as suicidal.

Three patients presented in such a way to invite speculation as to the possibility of serious organic disease, namely carcinomatous neuropathy, amytrophy and pancreatic disease and these were eliminated only after very full investigation.

It is of interest that with two patients their fathers died from carcinoma of the stomach and the bereavements were of some relevance. Regarding case 4 , with hysterical vomiting, it would be tempting to relate this to the father's illness but the fact is that vomiting was not a notable feature of the carcinoma.

The evidence points inescapably to a pattern of sexual activity well outside the normal range. Two patients were married; in one (case 5) the sexual aspect became non-existent and a source of discord and in the other (case 4) the presentation was atypical. There was decline in libido but this was not an important feature of the illness. Of the others, composed of late adolescents and young adults, it is doubtful it they had one act of intercourse to their credit (or discredit) between them.

There was no firm evidence of homosexuality. The authors are reluctant to use the description 'latent homosexuality' because of its nebulous nature and frequent misuse. A better alternative, however, cannot be found. There was a notable lack of assertive masculinity or identification with the normal interests and activities of the male age group. One 19-year-old was devoted to Old Time Dancing, another to tapestry and for another young man the Boys' Brigade was his main social outlet. These are commendable activities but they are probably significant in this context.

Hormonal studies were not undertaken routinely with these patients but having regard to indications that testosterone deficiency sometimes occurs, the help of endocrinologists is now a matter of routine. In case 2 , as indicated above, low testosterone figures were found. In most cases increased transaminase, blood urea and electrolyte disturbance reflected malnutrition and vomiting but were soon rectified. A malabsorption defect was found in one case (5) and, to a lesser extent, there have been similar findings in the case of two female anorexics. In one patient complex endocrine studies revealed a degree of hypopituitary failure but this reversed as he gained weight.

Apart from avoidance of food, especially carbohydrates, intermittent overeating occurred in five, and induced vomiting in three patients. No abnormal purging was admitted. The series included one 
TABLE 2

Family background

(a) Social class

(c) Parental age (at time of patient's birth)

(d) Nutritional

(e) Family history of anorexia

(f) Age
Present series

Crisp \& Toms, 1972

Parental social class was not recorded in two cases

Class II 3

Class III 5

(Registrar General's Classification, 1970)

1st-born

2nd-born

Youngest of 3

5

4

Mean paternal age 30

Mean maternal age 27

Nothing grossly abnormal in the bodyweight and shape of the parents was seen, apart from two mothers who were moderately obese and somewhat food conscious with sporadic dieting. In one case both parents were in the hotel business

Not seen in the present series (a twin brother and sister have presented subsequently)

Mean age of onset, 16.4 years (in at least four patients the onset occurred at the time of puberty)

Mean age of presentation 18.6 years
Class I and II 6/12

Class III-V 6/12

1st-born 7

2nd-born 5

Mean paternal age 31

Mean maternal age 29

Similar observations

Three siblings had this condition

$16 \cdot 2$ years

$19 \cdot 8$ years

Feeding Pattern

\begin{tabular}{|c|c|c|c|c|c|c|}
\hline \multirow[b]{2}{*}{ Clinical features } & & \multirow[b]{2}{*}{ Investigations } \\
\hline & $\begin{array}{l}\text { Abstain } \\
\text { (A) }\end{array}$ & $\begin{array}{l}\text { Overeating } \\
\text { (B) }\end{array}$ & $\begin{array}{l}\text { Vomiting } \\
\text { (V) }\end{array}$ & $\begin{array}{l}\text { Purging } \\
\text { (P) }\end{array}$ & $\begin{array}{l}\text { Alcohol or } \\
\text { drugs }\end{array}$ & \\
\hline 1 & $\times$ & $\times$ & $\times \times$ & - & - & \\
\hline 2 & $\times$ & $x$ & - & - & - & $\begin{array}{l}\text { High faecal fats following gastroenteritis } \\
\text { (this started in April and settled in Oct. } \\
\text { 1971) with a high SGOT, low folic acid }\end{array}$ \\
\hline 3 & $\times$ & - & - & - & - & Eosinophilia $17 \%$ \\
\hline 4 & $x$ & - & $\times \times$ & - & - & $\left.\begin{array}{l}\text { Blood urea raised } \\
\text { SGOT raised } \\
\text { low folic acid }\end{array}\right\} \begin{array}{l}\text { Settled after } 10-14 \\
\text { days }\end{array}$ \\
\hline 5 & $x$ & $\times$ & - & - & - & \\
\hline 6 & $x$ & $x$ & - & - & - & Blood urea raised (normal after ten days) \\
\hline 7 & $\times$ & - & 一 & - & - & \\
\hline 8 & $\times$ & - & - & - & - & \\
\hline 9 & - & $\times$ & $\times \times \times$ & - & - & $\begin{array}{l}\text { Low potassium, blood urea raised (settled } \\
\text { after } 16 \text { days) }\end{array}$ \\
\hline 10 & $x \times$ & $\times$ & $\times$ & - & Alcoholism & \\
\hline
\end{tabular}

dullard, and three patients with superior intelligence, the remainder being average. Although not formally tested, obsessionality seemed to be a prominent feature of the personality.

\section{Treatment}

Treatment was along the general lines of operant conditioning with flexibility according to the needs of a particular case. For the most part patients enjoyed increasing activity and autonomy as the required weight was attained. One or two patients actively enjoyed the hospital experience, or could not face home, and they were put in the paradoxicat position that they would be discharged if the weight were not attained. Chemotherapy was mainly at symptomatic level; massive doses of chlorpromazing were prescribed only exceptionally. Two patients hat received ECT elsewhere before referral to us but with unimpressive results. Pains were taken to study usually with the help of a social worker, the family and to include this in the framework of treatment? The employment of systematic psychotherapy waso not appropriate to all cases but when it was, the commencement of treatment was above all a matte $\$$ 
of timing; this proved abortive if undertaken too soon.

\section{Follow-up}

One patient (case 4) died. For the remainder, the length of follow-up (which was personal except in two cases where detailed and reliable reports were received) was from 6 months to 6 years (mean 27 months).

The earlier pattern was the familiar one of very uncertain maintenance of weight-gain, often with early re-admission. In the longer term one patient (case 5) has moved to the London area and is now awaiting re-admission, having relapsed into a chronic anorexic condition with a generally unsatisfactory life pattern. In two other patients the situation remains precarious. None has developed a bulimic syndrome.

From the psychiatric point of view four patients are entirely satisfactory, three patients have fairly prominent but not incapacitating anxiety symptoms or affective disturbances, and one has minor symptoms of that kind. One patient is frankly maladjusted.

Dally (1969) and Crisp and Toms (1972) have commented on the rather poorer prognosis in the male anorexic compared with the female counterpart. The authors' general impression is that the outcome in this series has been rather better than in their female cases but the numbers are small and it is possible that the sample, whilst undoubtedly fitting the category of weight phobia, contained a smaller proportion of extremely severe cases at the time of presentation compared with corresponding females.

\section{Conclusions}

The features displayed by the patients in this series show a great deal in common with those described by other authorities, especially Crisp and Toms (1972). This would seem to strengthen the authors' suspicion that they are dealing with a discrete syndrome. Discounting the amenorrhoea, the findings whilst showing divergences here and there are such as to make it more than likely that it is the male counterpart of primary anorexia nervosa in the female. No single finding can be identified as being essential but the aetiological package seems to include an obsessional personality, skewed parental relationships, self-consciousness about being overweight and importantly an apprehension of the threat of manhood, with particular reference to the heteroxexual role.

The significance of the cluster of psychological data is inescapable and it would stretch plausibility beyond reason to regard this as coincidental or secondary to a primary endocrine disturbance. The suggestion is that the disorder is primarily psychogenic although perhaps occurring in those with some physiological predisposition.

\section{Acknowledgments}

We are grateful to Professor A. H. Crisp for his comments and advice; to Professor Myre Sim, Dr Howard White and Dr Dennis Morgan for allowing us to include cases treated under their care; to the physicians Dr Trevor Cooke, Dr Stephen Whittaker, Dr Clifford Hawkins, and Dr Litchfield; to the statistical department Queen Elizabeth Hospital; and to Miss B. Tyler for secretarial assistance.

\section{References}

Bliss, E.L. \& Branch, C.H.H. (1960) Anorexia Nervosa, Its History, Psychology and Biology. Paul B. Hoeber Inc., Bearwood, New York.

BruCH, H. (1973) Eating Disorder. Routledge \& Kegan Paul, London.

CRISP, A.H. (1970) Anorexia nervosa, 'feeding disorder', 'nervous malnutrition' or 'weight phobia'? World Review of Nutrition and Dietetics, 12, 452.

Crisp, A.H., Palmer, R.L. \& Kalucy, R.S. (1976) How common is anorexia nervosa? A prevalence study. British Journal of Psychiatry, 128, 555.

CrisP, A.H. \& ToMS, D.A. (1972) Primary anorexia nervosa or weight phobia in the male; report on thirteen cases. British Medical Journal, 1, 334.

Dally, P. (1969) Anorexia Nervosa. Heinemann, London.

Kendell, R.E., Hall, D.J., Hailey, A. \& Babigian, H.M. (1973) The epidemiology of anorexia nervosa. Psychological Medicine, 3, 200.

Theander, S. (1970) A psychiatric investigation of 94 female patients. Acta psychiatrica scandinavica (Suppl. 214), 29. 